\title{
A comparative study of postpartum intrauterine contraceptive device acceptance between primiparous and multiparous women in a tertiary care centre
}

\author{
Sushila Kharkwal, Sanjaya Sharma, Kumari Manisha*
}

Department of Obstetrics and Gynaecology, MLB Medical College, Jhansi, Uttar Pradesh, India

Received: 15 May 2016

Accepted: 06 June 2016

*Correspondence:

Dr. Kumari Manisha,

E-mail: sandhyafms.sk@gmail.com

Copyright: (c) the author(s), publisher and licensee Medip Academy. This is an open-access article distributed under the terms of the Creative Commons Attribution Non-Commercial License, which permits unrestricted non-commercial use, distribution, and reproduction in any medium, provided the original work is properly cited.

\section{ABSTRACT}

Background: According to Census 2011 the population of India on 1 March 2011 was 1, 210, 193, 422. In spite of availability of wide range of contraceptives, the unmet need for family planning in India is estimated to be $21.3 \%$ by DLHS III survey. IUDs are the most commonly used method of reversible contraception worldwide.

Methods: It was a prospective, comparative, interventional study conducted over a period of one year at department of obstetrics and gynaecology, MLB medical college Jhansi, comprised of 306 women divided into two groups. Females in group A (129) were primiparous and in group B (207) were multiparous. All antenatal women between 36-42 weeks of gestation who anticipate delivery and counseled were included. Medical eligibility criteria were used for client assessment.

Results: Majority of the females (around 50\%) in both groups counseled prior to caesarean section. Around 43.7\% females in both groups were counseled during early labour. Rest 5\% females were counseled during their antenatal visits. There were $57.85 \%$ multiparous women who accepted PPIUCD. In primiparous women acceptance of PPIUCD was $42.15 \%$. Acceptance of postpartum intrauterine contraceptive devices (PPIUCD) was significantly higher in multipara (57.85\%). Most common reason behind acceptance was postpartum family planning (PPFP) counseling $(\sim 60 \%)$. Most common reason in multiparous women $(57.84 \%)$ was completed family. Others common reasons were motivated by ASHA (11.11\%), 6.54\% wanted birth spacing.

Conclusions: Acceptance of PPIUCD was significantly higher in multiparous women than primiparous. Most common reason behind this increased acceptance was PPFP counseling.

Keywords: PPIUCD, Acceptance, PPFP counseling

\section{INTRODUCTION}

According to Census 2011 the population of India on 1 March 2011 was $1,210,193,422 .^{1}$ In spite of availability of wide range of contraceptives, the unmet need for family planning in India is estimated to be $21.3 \%$ by DLHS III survey. ${ }^{2}$ Family planning is important not only for population stabilization, but it has been increasingly realized that family planning is central to improve maternal and new-born survival and health. ${ }^{3}$ The common reasons for unmet need are unsatisfactory services, lack of information, and fear about side effects of contraceptive methods. Apart from lactational amenorrhea, the methods which can be used by the women during postpartum period are barrier methods, progesterone only pills, sterilization and postpartum IUCD. IUDs provide a high level of efficacy in the absence of systemic metabolic effects, and on-going motivation is not required to ensure efficacy once the device has been placed. ${ }^{4}$ IUDs are the most commonly used method of reversible contraception worldwide. 5 Studies show that pregnancies taking place within 24 months of previous birth have higher risk of adverse outcome like abortion, premature labour, postpartum haemorrhage, low birth weight babies, fetal loss, and maternal death. ${ }^{6,7}$ Grimes and colleagues concluded that 
it is safe to do immediate postpartum IUCD insertion. ${ }^{8}$ Integrating IUCD insertion with delivery services optimizes opportunities for women to obtain an appropriate long term, reversible family planning method before returning home.

\section{METHODS}

This is a prospective interventional study to compare the acceptance of PPIUCD between primiparous and multiparous women delivered (either by caesarean section or by normal vaginal delivery) at department of obstetrics and gynaecology, MLB medical college Jhansi, between May 2014 to September 2015. Factors influencing acceptance were also assessed. Study comprised of 306 females divided into two groups. Females in group A (129) were primiparous and in group B (177) were multiparous. All antenatal women between 36 to 42 weeks of gestation attending the OPD/emergency or admitted in the ward who anticipate delivery (vaginal/c-section) and counselled for PPIUCD were included. PPFP Counselling was done as a part of study either during their antenatal visit or while preparing for a scheduled caesarean section or early labour or postpartum period (within 48 hours). If females were willing to use PPIUCD then we used WHO medical eligibility criteria for client assessment, Table 1. ${ }^{1}$ Follow up schedule was at 6 weeks after cut 380 A was used as PPIUCD insertion. Percentage and chi- square test were used for statistical analysis.

\section{RESULTS}

Table 1: WHO Medical eligibility criteria for client assessment.

\begin{tabular}{|c|c|}
\hline Category 1 & $\begin{array}{l}\text { Condition for which there is no restriction } \\
\text { for the use of the contraceptive method. } \\
\text { Safely use. }\end{array}$ \\
\hline Category 2 & $\begin{array}{l}\text { Condition where the advantages of using } \\
\text { the method generally outweigh the } \\
\text { theoretical or proven risks. Generally use. }\end{array}$ \\
\hline Category 3 & $\begin{array}{l}\text { Condition where the theoretical or proven } \\
\text { risks usually outweigh the advantages of } \\
\text { using the method. Generally do not use. }\end{array}$ \\
\hline Category 4 & $\begin{array}{l}\text { Condition which represents an } \\
\text { unacceptable health risk if the } \\
\text { contraceptive method is used. Do not use. }\end{array}$ \\
\hline
\end{tabular}

Majority of the females (around 50\%) in both groups counselled prior to caesarean section. Around $43.7 \%$ females in both groups were counselled during early labour. Rest $5 \%$ females were counselled during their antenatal visits. There were $57.85 \%$ multiparous women who accepted PPIUCD. In primiparous women acceptance of PPIUCD was $42.15 \%$. Acceptance of PPIUCD was significantly higher in multiparous women. Most common reason $(57.84 \%)$ for acceptance of PPIUCD in multiparous women was completed family. Other reasons for acceptance of PPIUCD were common in both groups. Most common reason in both groups which accounted for around 60\% was PPFP counselling whether antenatal, during early labour or prior to caesarean section. Around $11 \%$ were motivated by ASHA and $6.54 \%$ wanted birth spacing. Common reasons behind low acceptance of PPIUCD in primiparous women were have only female babies, fear of complications, denial by husband, IUD baby, preferred another method.

Table 2: Influence of parity on the acceptance of PPIUCD.

\begin{tabular}{|lll|ll|}
\hline & Primipara & Multipara & Total & pvalue \\
\hline PPIUCD & 129 & 177 & \multirow{2}{*}{306} & $<0.05$ \\
acceptance & $(42.15 \%)$ & $(57.85 \%)$ & & \\
\hline
\end{tabular}

Table 3: Type of counselling.

\begin{tabular}{|lllll|}
\hline & $\begin{array}{l}\text { During } \\
\text { early labour }\end{array}$ & $\begin{array}{l}\text { Prior to } \\
\text { LSCS }\end{array}$ & Antenatal & Total \\
\hline Group & 134 & 156 & 16 & 306 \\
A+B & $(26.12 \%)$ & $(30.40 \%)$ & $(3.12 \%)$ & 306 \\
\hline
\end{tabular}

Table 3: Reasons behind acceptance of PPIUCD in both groups.

\begin{tabular}{|ll|}
\hline Reasons & Number of females \\
\hline Counselling & $60.13 \%$ \\
\hline Family completed & $22.22 \%$ \\
\hline Motivated by ASHA & $11.11 \%$ \\
\hline Wanted birth spacing & $6.54 \%$ \\
\hline
\end{tabular}

\section{DISCUSSION}

Acceptance of PPIUCD was significantly higher in multipara $(57.85 \%)$. Similar findings were reflected in the study done by Safwat et al in Egypt, where $16 \%$ of primiparous accepted the use of PPIUCD compared to one third of grand multiparous. ${ }^{10}$ Most common reason behind acceptance was PPFP counseling ( 60\%). Most common reason in multiparous women $(57.84 \%)$ was completed family. Others common reasons were motivated by ASHA (11.11\%), 6.54\% wanted birth spacing. According to Katheit $G$ et al acceptance of PPIUCD was higher in para-2 (family completed) clients. ${ }^{9}$ Females who have only girl living child was the most common reason for low acceptance of PPIUCD in primiparous women. Fear of complications, preference to another method, denial by husband and IUD baby were other reasons. In a study done in Egypt, among the $71.1 \%$ women who refused the IUCD, planning another pregnancy in the near future $(34.3 \%)$ was the most common reason followed by preference of interval IUCD $(30.2 \%)$ and lactational amenorrhea (9.3\%). Complications from previous use of IUCD $(9.7 \%)$ or absence of husbands (3.4\%) were some other reasons. ${ }^{10}$ 


\section{CONCLUSION}

Acceptance of PPIUCD was significantly higher in multiparous women than primiparous. Most common reason behind this increased acceptance was PPFP counselling. Major reasons behind low acceptance in primiparous women were mainly social and psychological fear and taboos which needs more counselling and workup.

Funding: No funding sources

Conflict of interest: None declared

Ethical approval: All procedures performed in studies involving human participants were in accordance with the ethical standards of the institutional and/or national research committee and with the 1964 Helsinki declaration and its later amendments or comparable ethical standards

\section{REFERENCES}

1. Census of India, provisional population totals, figures at a glance; 2011.

2. District level household and facility survey III (DLHS III). Ministry of health and family welfare, Government of India; 2007-08.

3. IUCD reference manual for medical officers and nursing personnel; 2013.
4. Hall JE. The female reproductive system, infertility and contraception, Harrison's principles of internal medicine, $18^{\text {th }}$ edition, chapter; 347:3037-38.

5. Williams textbook of Obstetrics, $23^{\text {rd }}$ edition, Contraception, chapter 32; 684 .

6. Conde-Agudelo A, Belizan JM. Maternal morbidity and mortality associated with inter pregnancy interval: cross sectional study. $\mathrm{Br}$ Med J. 2000;321(7271):1255-9.

7. Conde-Agudelo A, Rosas-Bermúdez A, KafuryGoeta AC. Birth spacing and the risk of adverse perinatal outcomes: a meta-analysis. JAMA. 2006;295(15):1809-23.

8. Grimes DA, Schulz KF, Van Vliet H, Stanwood N. Immediate post-partum insertion of intrauterine devices. Cochrane Database Syst Rev. 2003(1):CD003036.

9. Katheit G, Agarwalet J. Evaluation of post-placental intrauterine device (PPIUCD) in terms of awareness, acceptance, and expulsion in a tertiary care centre. Int J Reprod Contracept Obstet Gynecol. 2013;2(4):539-43.

10. Mohamed SA, Kamel MA, Shaaban OM, Salem HT. Acceptability for the use of postpartum intrauterine contraceptive devices: The Assiut experience. Med Princ Pract. 2003;12(3):170-5.

Cite this article as: Kharkwal S, Sharma S, Kumari M. A comparative study of postpartum intrauterine contraceptive device acceptance between primiparous and multiparous women in a tertiary care centre. Int J Reprod Contracept Obstet Gynecol 2016;5:2304-6. 